\title{
Estimation of Tracheal Pressure and Imposed Expiratory Work of Breathing by the Endotracheal Tube, Heat and Moisture Exchanger, and Ventilator During Mechanical Ventilation
}

\author{
Akinori Uchiyama MD PhD, Takeshi Yoshida MD, Hidenori Yamanaka MD, \\ and Yuji Fujino MD PhD
}

\begin{abstract}
BACKGROUND: The resistance of the endotracheal tube (ETT), the heat and moisture exchanger (HME), and the ventilator may affect the patient's respiratory status. Although previous studies examined the inspiratory work of breathing (WOB), investigation of WOB in the expiratory phase is rare. We estimated tracheal pressure at the tip of the ETT $\left(P_{\text {trach }}\right)$ and calculated expiratory WOB imposed by the ETT, the HME, and the expiratory valve. We examined imposed expiratory WOB in patients under a continuous mandatory ventilation (CMV) mode and during spontaneous breathing trials (SBTs). We hypothesized that imposed expiratory WOB would increase with heightened ventilatory demand. METHODS: We measured airway pressure $\left(P_{\text {aw }}\right)$ and respiratory flow $(\dot{V})$. We estimated $P_{\text {trach }}$ using the equation $P_{\text {trach }}=P_{a w}-K_{1} \times \dot{V}^{K_{2}}-2.70 \times \dot{V}(L / s){ }^{1.42} \cdot K_{1}$ and $K_{2}$ were determined by the inner diameter (ID) of the ETT. Imposed expiratory WOB was calculated from the area of $P_{\text {trach }}$ above PEEP versus lung volume. We examined imposed expiratory WOB and imposed expiratory resistance in relation to mean expiratory flow. RESULTS: We examined 28 patients under CMV mode, and 29 during SBT. During both CMV and SBT, as mean expiratory flow increased, imposed expiratory WOB increased. The regression curves between mean expiratory flow $(x)(L / s)$ and imposed expiratory WOB $(y)(J / L)$ were $y=1.35 x^{0.83}\left(R^{2}=0.79\right)$ for $7 \mathrm{~mm}$ ID ETT under CMV, $y=1.12 x^{0.82}\left(R^{2}=0.73\right)$ for $8 \mathrm{~mm}$ ID ETT under CMV, $y=1.07 x^{1.04}$ $\left(R^{2}=0.85\right)$ for $7 \mathrm{~mm}$ ID ETT during SBT, and $y=0.84 x^{0.93}\left(R^{2}=0.75\right)$ for $8 \mathrm{~mm}$ ID ETT during SBT. Levels of imposed expiratory WOB were affected by ETT diameter and ventilator mode. The reason for increasing imposed expiratory WOB was an increase in expiratory resistance imposed by the ETT and HME. CONCLUSIONS: Under mechanical ventilation, imposed expiratory WOB should be considered in patients with higher minute ventilation. Key words: tracheal pressure; work of breathing; endotracheal tube; heat and moisture exchanger; ventilator; mechanical ventilation; resistance. [Respir Care 2013;58(7):1157-1169. (C) 2013 Daedalus Enterprises]
\end{abstract}

\section{Introduction}

Mechanical ventilation serves as an important method of treating patients with respiratory failure, and endotra-

\footnotetext{
The authors are affiliated with the Department of Anesthesiology and Intensive Care Medicine, Osaka University Graduate School of Medicine, Osaka, Japan.

This research was partly supported by grants 20591828 and 23592286 from the Japan Society for the Promotion of Science, Tokyo, Japan. The authors have disclosed no conflicts of interest.
}

Correspondence: Akinori Uchiyama MD PhD, Department of Anesthe- cheal intubation is a procedure performed during mechanical ventilation in the majority of such patients. When a person has an endotracheal tube (ETT) inserted, the normal humidifying function of the upper airway is bypassed. Because inhaling cold, dry gases leads to complications, it is necessary to provide humidification of the incoming air. ${ }^{1,2}$ There are 2 main methods of humidification, a heated

\footnotetext{
siology and Intensive Care Medicine, Osaka University Graduate School Medicine, Yamadaoka 2-15, Suita, Osaka 565-0871, Japan. E-mail: auchiyama@hp-icu.med.osaka-u.ac.jp.
}

DOI: $10.4187 /$ respcare. 01698 
humidifier and a heat and moisture exchanger (HME), during mechanical ventilation. The HME is now widely used. ${ }^{1}$ While gas is actively heated and moistened by the heated humidifier in the inspiratory limb of the ventilatory circuit, gas is passively humidified by the media of the HME connected between the ETT and the ventilatory circuit. ${ }^{1}$ The ETT and HME both offer resistance to gas flow, which increases the patient's respiratory load. The resistance of the expiratory valve of the ventilator may also affect the patient's respiratory status.

Inspiratory work of breathing (WOB) during mechanical ventilation has been examined in previous studies. ${ }^{3-8}$ Pressure support ventilation (PSV) has been developed to achieve a decrease in inspiratory WOB..$^{3-5}$ Only an automatic tube compensation mode has been developed to counteract additional WOB during inspiration and expiration. ${ }^{3,6,9}$ However, WOB in the expiratory phase has rarely been investigated. The resistance of an ETT and an HME and an expiratory valve of a given ventilator might increase respiratory load during expiration. Total expiratory WOB experienced by the patient is equal to the sum of expiratory WOB by the lungs and imposed expiratory WOB. Imposed expiratory WOB adds to the total expiratory WOB experienced by the patient, and increases expiratory load on the patient.

Increased expiratory load induces lung hyperinflation in passive expiration or active expiratory effort, sometimes inducing problems such as lung injury, circulatory depression, or increased energy demands in critically ill patients. ${ }^{10-13}$ Patients receiving mechanical ventilation often need greater amounts of ventilation than do healthy subjects because of abnormal lung function and/or increased metabolic demand. ${ }^{14}$ The respiratory load imposed by an ETT, an HME, or an expiratory valve would therefore increase in such patients. We hypothesized that the expiratory load imposed on patients by an ETT, an HME, or an expiratory valve of the ventilator would increase in the case of high ventilatory demand. We examined imposed expiratory WOB and imposed expiratory resistance $\left(\mathrm{R}_{\mathrm{E}}\right)$ in relation to mean expiratory flow. We measured the estimated tracheal pressure at the tip of the ETT $\left(\mathrm{P}_{\text {trach }}\right)$ to calculate imposed expiratory WOB and imposed expiratory $\mathrm{R}_{\mathrm{E}}$ by the ETT, the HME, and the expiratory valve of the ventilator, among patients receiving mechanical ventilation in the ICU.

\section{Methods}

The study protocol was approved by the ethics committee of Osaka University Hospital (approval 8270) and performed in accordance with the Declaration of Helsinki. Written consent was obtained from patients' family members. Patients under mechanical ventilation were studied in an ICU at Osaka University Hospital. We excluded tra-

\section{QUICK LOOK}

\section{Current knowledge}

Inspiratory work of breathing imposed by the endotracheal tube, humidifier, and ventilator alter patient comfort and respiratory status. Smaller tube diameter, larger equipment dead space, and inappropriate ventilator settings are associated with greater imposed work. Under passive conditions during mechanical ventilation, expiratory work is considered negligible.

\section{What this paper contributes to our knowledge}

During mechanical ventilation at high minute volumes, the imposed expiratory work of breathing created by the endotracheal tube, heat and moisture exchanger, and expiratory valve increased with increasing expiratory flow. These effects may lead to increased intrinsic PEEP and hyperinflation.

cheostomized patients. The study was performed between September 2009 and May 2010.

\section{Method of Estimation of $P_{\text {trach }}$}

All patients were ventilated using the same ventilator (Nellcor Puritan Bennett 840, Covidien, Boulder, Colorado). A disposable HME (DAR Hygrobac S, Covidien, Boulder, Colorado) and an ordinary disposable ventilatory circuit (DAR adult breathing circuit, Covidien, Boulder, Colorado) were used. The HME was replaced prior to each measurement. We measured airway pressure $\left(\mathrm{P}_{\mathrm{aw}}\right)$ and respiratory flow $(\dot{V})$ during mechanical ventilation. $\mathrm{P}_{\text {aw }}$ was measured on the ventilator side of the HME. A differential pressure transducer (TP603T, Nihon Kohden, Tokyo, Japan) and an amplifier (AR601G, Nihon Kohden, Tokyo, Japan) were used to measure $\mathrm{P}_{\mathrm{aw}}$. Patient air flow was measured using a pneumotachograph (4705, Hans Rudolph, Shawnee, Kansas), a differential pressure transducer (TP602T, Nihon Kohden, Tokyo, Japan), and an amplifier (AR601G, Nihon Kohden, Tokyo, Japan). The pneumotachograph was placed between the HME and the ventilatory circuit. The data output from the amplifiers was recorded and analyzed by a data acquisition system (WINDAQ, Dataq Instruments, Akron, Ohio). The data sampling frequency of each signal was set at $100 \mathrm{~Hz}$.

We estimated $\mathrm{P}_{\text {trach }}$ by the following equation, by subtraction of the pressure drop caused by the ETT $\left(\Delta \mathrm{P}_{\mathrm{ETT}}\right)$, the $\operatorname{HME}\left(\Delta \mathrm{P}_{\mathrm{HME}}\right)$, or the pneumotachograph $\left(\Delta \mathrm{P}_{\mathrm{PT}}\right)$ from the $\mathrm{P}_{\mathrm{aw}}$ :

$$
\mathrm{P}_{\text {trach }}=\mathrm{P}_{\mathrm{aw}}-\left(\Delta \mathrm{P}_{\mathrm{ETT}}+\Delta \mathrm{P}_{\mathrm{HME}}+\Delta \mathrm{P}_{\mathrm{PT}}\right)
$$


Several mathematic models were used to approximate the measured pressure-flow dependence, ${ }^{15,16}$ one of which was a combined linear and quadratic approximation:

$$
\mathrm{P}=\mathrm{K}_{1} \times \dot{\mathrm{V}}^{2}+\mathrm{K}_{2} \times \dot{\mathrm{V}}
$$

Another model was a nonlinear approximation:

$$
\mathrm{P}=\mathrm{K}_{1} \times \dot{\mathrm{V}}^{\mathrm{K}_{2}}
$$

We decided on the appropriate approximation equations for the ETT, HME, and pneumotachograph according to the results of previous studies and from regression analysis. ${ }^{15,16}$

We estimated $\Delta \mathrm{P}_{\mathrm{ETT}}$ by the equation

$$
\Delta \mathrm{P}_{\mathrm{ETT}}\left(\mathrm{cm} \mathrm{H} \mathrm{H}_{2} \mathrm{O}\right)=\mathrm{K}_{1} \times \dot{\mathrm{V}}(\mathrm{L} / \mathrm{s})^{\mathrm{K}_{2}}
$$

according to the study of Guttmann et al. ${ }^{15}$ The constants of the equation $\left(\mathrm{K}_{1}\right.$ and $\left.\mathrm{K}_{2}\right)$ were determined by ETT diameter and the direction of respiratory flow. ${ }^{15}$ The values for $\mathrm{K}_{1}$ and $\mathrm{K}_{2}$ during inspiration were $11.12 \mathrm{~cm} \mathrm{H}_{2} \mathrm{O} \cdot \mathrm{s} / \mathrm{L}$ and $1.99 \mathrm{~cm} \mathrm{H}_{2} \mathrm{O} \cdot \mathrm{s} / \mathrm{L}$, respectively, using the $7 \mathrm{~mm}$ ID ETT, and $6.57 \mathrm{~cm} \mathrm{H}_{2} \mathrm{O} \cdot \mathrm{s} / \mathrm{L}$ and $1.94 \mathrm{~cm} \mathrm{H}_{2} \mathrm{O} \cdot \mathrm{s} / \mathrm{L}$, respectively, using the $8 \mathrm{~mm}$ ID ETT. ${ }^{15}$ The values for $\mathrm{K}_{1}$ and $\mathrm{K}_{2}$ during expiration were $11.69 \mathrm{~cm} \mathrm{H}_{2} \mathrm{O} \cdot \mathrm{s} / \mathrm{L}$ and $1.85 \mathrm{~cm} \mathrm{H}{ }_{2} \mathrm{O} \cdot \mathrm{s} / \mathrm{L}$, respectively, using the $7 \mathrm{~mm}$ ID ETT, and $7.50 \mathrm{~cm} \mathrm{H}_{2} \mathrm{O} \cdot \mathrm{s} / \mathrm{L}$ and $1.75 \mathrm{~cm} \mathrm{H}_{2} \mathrm{O} \cdot \mathrm{s} / \mathrm{L}$, respectively, using the $8 \mathrm{~mm}$ ID ETT. ${ }^{15}$ The equation for $\Delta \mathrm{P}_{\mathrm{HME}}$ obtained from the manufacturer's data was:

$$
\Delta \mathrm{P}_{\mathrm{HME}}\left(\mathrm{cm} \mathrm{H}_{2} \mathrm{O}\right)=\mathrm{K}_{3} \times \dot{\mathrm{V}}(\mathrm{L} / \mathrm{s})^{\mathrm{K}_{4}}
$$

where $\mathrm{K}_{3}=2.70$ and $\mathrm{K}_{4}=1.42\left(\mathrm{R}^{2}>0.99\right)$.

Because the pneumotachograph was not connected to the ordinary respiratory circuit, $\Delta \mathrm{P}_{\mathrm{PT}}$ should be taken into consideration to simulate the normal bedside situation. The equation for $\Delta \mathrm{P}_{\mathrm{HME}}$ obtained from the manufacturer's data was:

$$
\Delta \mathrm{P}_{\mathrm{PT}}\left(\mathrm{cm} \mathrm{H}_{2} \mathrm{O}\right)=\mathrm{K}_{5} \times \dot{\mathrm{V}}(\mathrm{L} / \mathrm{s})^{2}+\mathrm{K}_{6} \times \dot{\mathrm{V}}(\mathrm{L} / \mathrm{s})
$$

where $\mathrm{K}_{5}=0.72$ and $\mathrm{K}_{6}=0.71\left(\mathrm{R}^{2}>=0.99\right)$. Because the measurement site of $\mathrm{P}_{\mathrm{aw}}$ was set at the patient's side of the pneumotachograph, the correction by using $\Delta \mathrm{P}_{\mathrm{PT}}$ was performed only during the expiration. Therefore, we estimated $\mathrm{P}_{\text {trach }}$ according to the following equations. In patients with a $7 \mathrm{~mm}$ ID ETT:

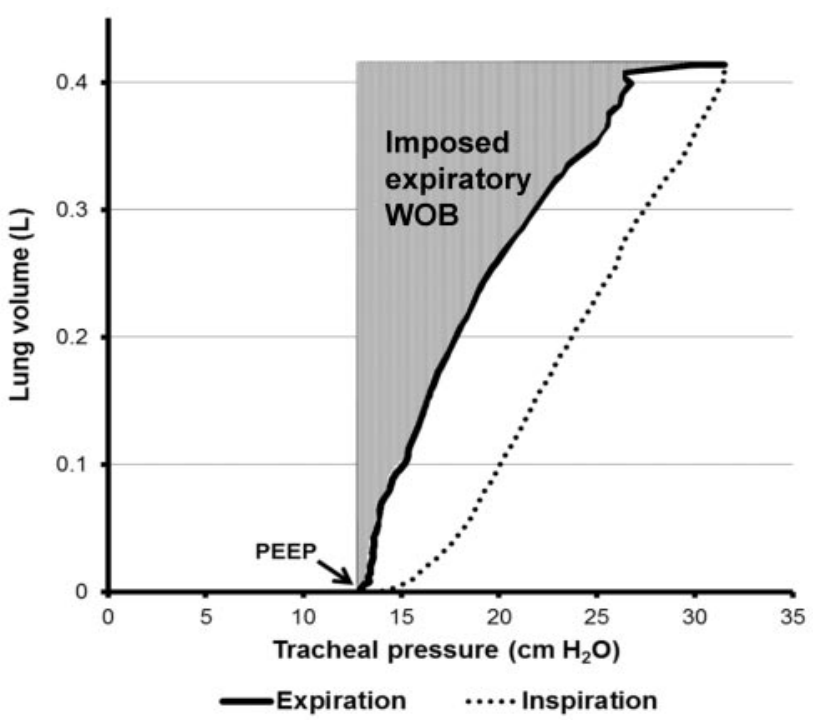

Fig. 1. Tracheal pressure at the tip of the endotracheal tube $\left(P_{\text {trach }}\right)$ versus lung volume loop. Imposed expiratory work of breathing (WOB) was calculated from the area of $P_{\text {trach }}$ above PEEP versus the lung volume curve.

$$
\begin{array}{r}
\mathrm{P}_{\text {trach }}\left(\mathrm{cm} \mathrm{H}_{2} \mathrm{O}\right)=\mathrm{P}_{\mathrm{aw}}-11.12 \times \dot{\mathrm{V}}(\mathrm{L} / \mathrm{s})^{1.99}-2.70 \\
\times \dot{\mathrm{V}}(\mathrm{L} / \mathrm{s})^{1.42}
\end{array}
$$

during inspiration, and

$$
\begin{aligned}
& \mathrm{P}_{\text {trach }}\left(\mathrm{cm} \mathrm{H}_{2} \mathrm{O}\right)=\mathrm{P}_{\mathrm{aw}}+11.69 \times \dot{\mathrm{V}}(\mathrm{L} / \mathrm{s})^{1.85}+2.70 \\
& \times \dot{\mathrm{V}}(\mathrm{L} / \mathrm{s})^{1.42}-0.72 \times \dot{\mathrm{V}}(\mathrm{L} / \mathrm{s})^{2}-0.71 \times \dot{\mathrm{V}}(\mathrm{L} / \mathrm{s})
\end{aligned}
$$

during expiration.

In patients with an $8 \mathrm{~mm}$ ID ETT:

$$
\begin{array}{r}
\mathrm{P}_{\text {trach }}\left(\mathrm{cm} \mathrm{H}_{2} \mathrm{O}\right)=\mathrm{P}_{\mathrm{aw}}-6.57 \times \dot{\mathrm{V}}(\mathrm{L} / \mathrm{s})^{1.94}-2.70 \\
\times \dot{\mathrm{V}}(\mathrm{L} / \mathrm{s})^{1.42}
\end{array}
$$

during inspiration and

$$
\begin{gathered}
\mathrm{P}_{\text {trach }}\left(\mathrm{cm} \mathrm{H}_{2} \mathrm{O}\right)=\mathrm{P}_{\mathrm{aw}}+7.50 \times \dot{\mathrm{V}}(\mathrm{L} / \mathrm{s})^{1.75}+2.70 \\
\times \dot{\mathrm{V}}(\mathrm{L} / \mathrm{s})^{1.42}-0.72 \times \dot{\mathrm{V}}(\mathrm{L} / \mathrm{s})^{2}-0.71 \times \dot{\mathrm{V}}(\mathrm{L} / \mathrm{s})
\end{gathered}
$$

during expiration.

\section{Calculations}

Imposed Expiratory WOB. Imposed expiratory WOB was calculated from the area of $\mathrm{P}_{\text {trach }}$ above PEEP versus 
Table 1. Subject Characteristics

\begin{tabular}{|c|c|c|c|c|}
\hline & \multicolumn{2}{|c|}{$\begin{array}{c}\text { Continuous Mandatory Ventilation } \\
\text { Group }\end{array}$} & \multicolumn{2}{|c|}{$\begin{array}{c}\text { Spontaneous Breathing Trial } \\
\text { Group }\end{array}$} \\
\hline & \multicolumn{4}{|c|}{ ETT inner diameter, $\mathrm{mm}$} \\
\hline & 7 & 8 & 7 & 8 \\
\hline$n$ & 12 & 16 & 9 & 20 \\
\hline Age, mean $\pm \mathrm{SD}$ y & $56.6 \pm 16.8$ & $63.9 \pm 16.4$ & $56.2 \pm 16.7$ & $62.8 \pm 13.5$ \\
\hline Male, no. & 2 & 16 & 2 & 19 \\
\hline \multicolumn{5}{|l|}{ Body weight, mean $\pm \mathrm{SD} \mathrm{kg}$} \\
\hline Actual & $59.5 \pm 9.5$ & $60.1 \pm 10.8$ & $61.2 \pm 6.5$ & $66.3 \pm 10.7$ \\
\hline Predicted* & $51.7 \pm 10.0$ & $64.3 \pm 5.4 \dagger$ & $52.2 \pm 8.5 \ddagger$ & $65.3 \pm 6.4 \dagger \S$ \\
\hline Duration of mechanical ventilation, mean $\pm \mathrm{SD} d$ & $2.7 \pm 3.5$ & $4.2 \pm 3.4$ & $5.3 \pm 4.3$ & $3.9 \pm 2.0$ \\
\hline \multicolumn{5}{|l|}{ Diagnostic category, no. } \\
\hline Post cardiovascular surgery & 6 & 9 & 4 & 18 \\
\hline Post general surgery & 6 & 1 & 4 & 2 \\
\hline Medical & 0 & 6 & 1 & 0 \\
\hline \multicolumn{5}{|c|}{$\begin{array}{l}\text { * The predicted body weight of male subjects was calculated as } 50+0.91 \text { (centimeters of height-152.4); that of female subjects was calculated as } 45.5+0.91 \text { (centimeters of height-152.4). } \\
\dagger P<.001 \text { compared with continuous mandatory ventilation group with } 7 \mathrm{~mm} \text { endotracheal tube (ETT). } \\
\ddagger P=.001 \text { compared with continuous mandatory ventilation group with } 8 \mathrm{~mm} \text { ETT. } \\
\S P<.001 \text { compared with spontaneous breathing trial group with } 7 \mathrm{~mm} \text { ETT. }\end{array}$} \\
\hline
\end{tabular}

the lung volume curve, according to the equation shown in Figure 1.6,17 The PEEP level was determined as the average $\mathrm{P}_{\mathrm{aw}}$ during the final $5 \%$ of exhaled gas volume. WOB values were calculated by the following equation:

Estimated imposed expiratory WOB (J)

$$
=\int_{\mathrm{V}_{\mathrm{e} 0}}^{\mathrm{V}_{\mathrm{Te}}}\left(\mathrm{P}_{\text {trach }}-\mathrm{PEEP}\right) \mathrm{dV}
$$

where $\mathrm{V}=$ volume, $\mathrm{V}_{\mathrm{e} 0}=$ exhaled volume at the start of exhalation, and $\mathrm{V}_{\mathrm{Te}}=$ exhaled tidal volume. WOB values were shown as values per ventilation $(\mathrm{J} / \mathrm{L})$ by dividing the values of WOB by exhaled tidal volume. WOB values were also shown as values per minute $(\mathrm{J} / \mathrm{min})$.

\section{Ventilator-Imposed Expiratory Resistance}

$\mathrm{P}_{\mathrm{aw}}$-PEEP is the driving force that causes gas to flow through the ventilator. ${ }^{17}$ Ventilator-imposed $R_{E}$ is calculated as the integrated average resistance during exhalation, averaged by volume. ${ }^{17}$ Instantaneous resistance is integrated over $95 \%$ of the exhaled volume, and that integral is then divided by tidal volume to obtain ventilatorimposed $R_{E}$ :

$$
\text { Ventilator-imposed } R_{E}=\int_{V_{\mathrm{e} 0}}^{V_{\mathrm{e} 95}} \mathrm{RdV} \mid \int_{\mathrm{V}_{\mathrm{e} 0}}^{\mathrm{V}_{\mathrm{e} 95}} \mathrm{dV}
$$

where $\mathrm{R}=$ resistance, $\mathrm{V}=$ volume, $\mathrm{V}_{\mathrm{e} 0}=$ exhaled volume at the start of exhalation, and $\mathrm{V}_{\mathrm{e} 95}=$ exhaled volume at $95 \%$ of exhalation.

\section{Expiratory Resistance Imposed by the ETT and HME}

$\mathrm{P}_{\text {trach-PEEP is the driving force that causes gas to flow }}$ from the lung. Total imposed $\mathrm{R}_{\mathrm{E}}$ is also calculated as the integrated average resistance, using tracings of $\mathrm{P}_{\text {trach }}$ during exhalation, averaged by volume. $\mathrm{R}_{\mathrm{E}}$ imposed by ETT and HME is obtained from the following equation:

$$
\begin{array}{r}
\mathrm{R}_{\mathrm{E}} \text { imposed by the ETT and } \mathrm{HME}=\text { total imposed } \mathrm{R}_{\mathrm{E}} \\
\text { - ventilator-imposed } \mathrm{R}_{\mathrm{E}}
\end{array}
$$

\section{End-Expiratory $\mathbf{P}_{\text {trach }}$}

To evaluate the levels of intrinsic PEEP produced by imposed $R_{E}, P_{\text {trach }}$ essentially should be measured at the beginning of inhalation. However, this was difficult to measure because of our method of estimating $\mathrm{P}_{\text {trach }}$. Therefore, we measured end-expiratory $\mathrm{P}_{\text {trach }}$ as the average $\mathrm{P}_{\text {trach }}$ during the final $5 \%$ of exhaled gas volume. Because PEEP settings varied between the 4 groups, the values of end-expiratory $\mathrm{P}_{\text {trach }}$-PEEP setting were compared.

We also calculated other respiratory data from the tracings of $\mathrm{P}_{\mathrm{aw}}, \mathrm{P}_{\text {trach }}$, and flow. Mean expiratory flow was determined as the average flow during $95 \%$ of the tidal volume exhaled after the beginning of expiration. Tidal 


\begin{tabular}{|c|c|c|c|c|}
\hline & \multicolumn{2}{|c|}{$\begin{array}{l}\text { Continuous Mandatory } \\
\text { Ventilation Group }\end{array}$} & \multicolumn{2}{|c|}{$\begin{array}{c}\text { Spontaneous Breathing Trial } \\
\text { Group }\end{array}$} \\
\hline & \multicolumn{4}{|c|}{ ETT inner diameter } \\
\hline & 7 & 8 & 7 & 8 \\
\hline Breathing frequency, breaths/min & $19.4 \pm 6.5$ & $22.4 \pm 8.2$ & $16.0 \pm 4.7$ & $21.4 \pm 6.3$ \\
\hline Minute ventilation, $\mathrm{L} / \mathrm{min}$ & $9.1 \pm 3.6$ & $12.4 \pm 4.8$ & $7.7 \pm 3.3 \dagger$ & $9.0 \pm 1.9 \dagger$ \\
\hline Tidal volume, $\mathrm{mL} / \mathrm{kg}$ actual body weight & $8.1 \pm 1.7$ & $9.5 \pm 1.6$ & $8.4 \pm 3.9$ & $6.7 \pm 1.6 \dagger$ \\
\hline Tidal volume, $\mathrm{mL} / \mathrm{kg}$ predicted body weight & $9.4 \pm 2.1$ & $8.8 \pm 1.9$ & $9.4 \pm 2.9$ & $6.7 \pm 1.2 * \dagger+$ \\
\hline Inspiratory time, $\mathrm{s}$ & $1.12 \pm 0.18$ & $1.06 \pm 0.21$ & $1.29 \pm 0.16$ & $1.17 \pm 0.25$ \\
\hline Inspiratory $\mathrm{P}_{\mathrm{aw}}, \mathrm{cm} \mathrm{H}_{2} \mathrm{O}$ & $22.5 \pm 4.0$ & $23.5 \pm 5.6$ & $8.7 \pm 0.3 * \dagger$ & $8.5 \pm 0.3 * \dagger$ \\
\hline Inspiratory $\mathrm{P}_{\text {trach }}, \mathrm{cm} \mathrm{H}_{2} \mathrm{O}$ & $19.1 \pm 3.6$ & $19.9 \pm 5.2$ & $5.4 \pm 2.4 * \dagger$ & $6.5 \pm 0.5 * \dagger$ \\
\hline Expiratory time, $\mathrm{s}$ & $2.35 \pm 1.14$ & $2.07 \pm 1.19$ & $2.79 \pm 1.00$ & $1.86 \pm 0.64$ \\
\hline Expiratory $\mathrm{P}_{\mathrm{aw}}, \mathrm{cm} \mathrm{H}_{2} \mathrm{O}$ & $9.1 \pm 3.1$ & $10.7 \pm 4.0$ & $6.3 \pm 0.2 \dagger$ & $6.6 \pm 0.3 \dagger$ \\
\hline PEEP, $\mathrm{cm} \mathrm{H}_{2} \mathrm{O}$ & $8.1 \pm 2.3$ & $9.5 \pm 3.6$ & $6.2 \pm 0.2 \dagger$ & $6.3 \pm 0.4 \dagger$ \\
\hline Expiratory $\mathrm{P}_{\text {trach }}, \mathrm{cm} \mathrm{H}_{2} \mathrm{O}$ & $10.9 \pm 4.0$ & $13.0 \pm 4.4$ & $7.5 \pm 0.8 \dagger$ & $7.8 \pm 0.7 \dagger$ \\
\hline End-expiratory $\mathrm{P}_{\text {trach }}$ PEEP setting, $\mathrm{cm} \mathrm{H}_{2} \mathrm{O}$ & $1.1 \pm 0.7$ & $1.9 \pm 1.2$ & $1.4 \pm 0.4$ & $1.5 \pm 0.5$ \\
\hline Maximal expiratory flow, $\mathrm{L} / \mathrm{s}$ & $0.76 \pm 0.13$ & $0.89 \pm 0.14^{*}$ & $0.42 \pm 0.13^{* \dagger}$ & $0.48 \pm 0.07 * \dagger$ \\
\hline Expiratory flow, L/s & $0.31 \pm 0.11$ & $0.42 \pm 0.13^{*}$ & $0.23 \pm 0.07 \dagger$ & $0.29 \pm 0.07 \dagger$ \\
\hline Imposed expiratory WOB, J/L & $0.51 \pm 0.17$ & $0.55 \pm 0.14$ & $0.24 \pm 0.09 * \dagger$ & $0.27 \pm 0.06^{* \dagger} \dagger$ \\
\hline Imposed expiratory $\mathrm{WOB}, \mathrm{J} / \mathrm{min}$ & $5.18 \pm 3.79$ & $7.28 \pm 4.00$ & $2.06 \pm 1.67 \dagger$ & $2.48 \pm 1.02 \dagger$ \\
\hline Expiratory resistance imposed by ETT and HME, $\mathrm{cm} \mathrm{H}_{2} \mathrm{O} / \mathrm{L} / \mathrm{s}$ & $7.32 \pm 1.30$ & $6.52 \pm 0.86$ & $5.42 \pm 1.11^{* \dagger}$ & $4.97 \pm 0.59 * \dagger$ \\
\hline Ventilator-imposed expiratory resistance, $\mathrm{cm} \mathrm{H}_{2} \mathrm{O} / \mathrm{L} / \mathrm{s}$ & $3.63 \pm 2.98$ & $3.61 \pm 2.91$ & $1.82 \pm 0.32$ & $2.17 \pm 0.56$ \\
\hline $\mathrm{pH}$ & $7.42 \pm 0.06$ & $7.42 \pm 0.08$ & $7.42 \pm 0.06$ & $7.42 \pm 0.04$ \\
\hline $\mathrm{P}_{\mathrm{aCO}_{2}}, \mathrm{~mm} \mathrm{Hg}$ & $43 \pm 6$ & $43 \pm 11$ & $43 \pm 9$ & $43 \pm 5$ \\
\hline $\mathrm{P}_{\mathrm{aO}_{2}}, \mathrm{~mm} \mathrm{Hg}$ & $103 \pm 27$ & $133 \pm 57$ & $121 \pm 60$ & $162 \pm 56^{*}$ \\
\hline $\mathrm{P}_{\mathrm{aO}_{2}} / \mathrm{F}_{\mathrm{IO}_{2}}$ & $230 \pm 85$ & $271 \pm 150$ & $241 \pm 121$ & $324 \pm 112$ \\
\hline $\begin{array}{l}\text { Values are mean } \pm \mathrm{SD} \text {. } \\
* P<.05 \text { compared with continuous mandatory ventilation group with } 7 \mathrm{~mm} \text { endot } \\
\dagger P<.05 \text { compared with continuous mandatory ventilation group with } 8 \mathrm{~mm} \text { ETT. } \\
\ddagger P=.005 \text { compared with spontaneous breathing trial group with } 7 \mathrm{~mm} \text { ETT. } \\
\mathrm{P}_{\text {aw }}=\text { airway pressure } \\
\mathrm{P}_{\text {trach }}=\text { tracheal pressure at the tip of the ETT } \\
\text { WOB }=\text { work of breathing } \\
\text { HME }=\text { heat and moisture exchanger }\end{array}$ & ube (ETT). & & & \\
\hline
\end{tabular}

volume was evaluated by dividing actual tidal volume by predicted body weight, as same as the previous study. ${ }^{14}$ The predicted body weight of male patients was calculated as:

$$
50+0.91(\text { centimeters of height }-152.4)
$$

The predicted body weight of female patients was calculated as:

$$
45.5+0.91 \text { (centimeters of height }-152.4)
$$

\section{Protocol}

Patients were divided into 4 groups: 2 ventilatory modes (continuous mandatory ventilation [CMV]) mode, or spontaneous breathing trial [SBT] performed using a ventilator), and 2 inner diameter (ID) sizes of ETT (7 or $8 \mathrm{~mm}$ ).
Patients under mechanical ventilation in CMV mode for $>12 \mathrm{~h}$ were enrolled in the CMV mode study. In the CMV mode study the settings of $\mathrm{F}_{\mathrm{IO}_{2}}$, ventilatory rate, PEEP setting, inspiratory pressure control level, inspiratory time, and inspiratory triggering level were determined by the ICU physicians responsible for treatment. Patients being considered for removal from mechanical ventilatory support were enrolled in the SBT study. SBT was performed under CPAP plus PSV mode. Application and cessation of SBT were determined by the ICU physicians responsible for treatment. Patients who failed after $15 \mathrm{~min}$ of SBT were excluded. The settings of SBT were $5 \mathrm{~cm} \mathrm{H}_{2} \mathrm{O}$ of CPAP plus $5 \mathrm{~cm} \mathrm{H}_{2} \mathrm{O}$ of PSV. The triggering setting was $-1.5 \mathrm{~cm} \mathrm{H}_{2} \mathrm{O}$, and $\mathrm{F}_{\mathrm{IO}_{2}}$ was 0.50 . The setting for expiratory triggering was $25 \%$ of peak inspiratory flow.

We measured the estimated $\mathrm{P}_{\text {trach }}$ and other respiratory characteristic data, and calculated imposed expiratory WOB under either CMV mode or SBT. Patients were divided 
into 4 groups, by ventilatory mode and ID ETT (7 or $8 \mathrm{~mm}$ ). Imposed expiratory load is largely determined by the imposed $R_{E}$ and the level of expiratory flow. Mean expiratory flow is a key factor in examining expiratory load under mechanical ventilation. To compare the characteristics of the 4 groups, the relationships among mean expiratory flow and imposed WOB and $R_{E}$ were examined. Measurements were recorded after ventilatory settings had been stable for $>15 \mathrm{~min}$. Data were acquired from tracings of stable, consecutive breaths over $1 \mathrm{~min}$.

\section{Statistical Analysis}

Respiratory data were expressed as mean \pm SD. Differences in the data of each group were tested by one-way factorial analysis of variance, followed by a Scheffé multiple comparison post hoc test. If the Pearson correlation coefficient between the mean expiratory flow and imposed expiratory WOB, $\mathrm{R}_{\mathrm{E}}$ imposed by ETT and HME, ventilator-imposed $\mathrm{R}_{\mathrm{E}}$, or end-expiratory $\mathrm{P}_{\text {trach }}$-PEEP setting were significant, regression analysis was then performed. Regression curves from mean expiratory flow to these were obtained by the statistical analysis function of spreadsheet software (Excel 2010, Microsoft, Redmond, Washington). Approximation was performed by the least squares method, using either the linear expression model, quadratic expression model, power expression model, exponential expression model, or logarithmic expression model. Regression curves were excluded if their shape was not suitable for approximation. Values of the coefficient of determination in each model were used to determine the most appropriate expression model. Differences among the regression plots of each group were checked by analysis of covariance. $P<.05$ was considered significant. Statistical analysis was performed using statistics software (the Japanese version of SPSS 16.0, SPSS, Chicago, Illinois).

\section{Results}

The patient characteristics for each group are shown in Table 1. The percentage of male patients with $8 \mathrm{~mm}$ ID ETT was higher than the others. The predicted body weights of patients with $8 \mathrm{~mm}$ ID ETT was higher than the others. In patients with 7 and $8 \mathrm{~mm}$ ID ETTs the ventilatory settings under CMV mode were as follows: $\mathrm{F}_{\mathrm{IO}_{2}} 0.45 \pm 0.07$ and $0.44 \pm 0.05$, ventilatory rate $16.8 \pm 5.6$ breaths $/ \mathrm{min}$ and $18.2 \pm 7.90$ breaths $/ \mathrm{min}$, inspiratory pressure control level $16.5 \pm 3.5 \mathrm{~cm} \mathrm{H}_{2} \mathrm{O}$ and $16.7 \pm 3.4 \mathrm{~cm} \mathrm{H}_{2} \mathrm{O}$; inspiratory time $1.06 \pm 0.15 \mathrm{~s}$ and $1.06 \pm 0.18 \mathrm{~s}$; and PEEP $7.4 \pm 2.1 \mathrm{~cm} \mathrm{H}_{2} \mathrm{O}$ and $8.5 \pm 3.7 \mathrm{~cm} \mathrm{H}_{2} \mathrm{O}$. Measured ventilatory data are shown in Table 2. Some measured ventilatory data varied among groups because of differences in ETT size, ventilatory mode, and ventilatory settings. Mean expiratory flow is proportional to minute ven-
A
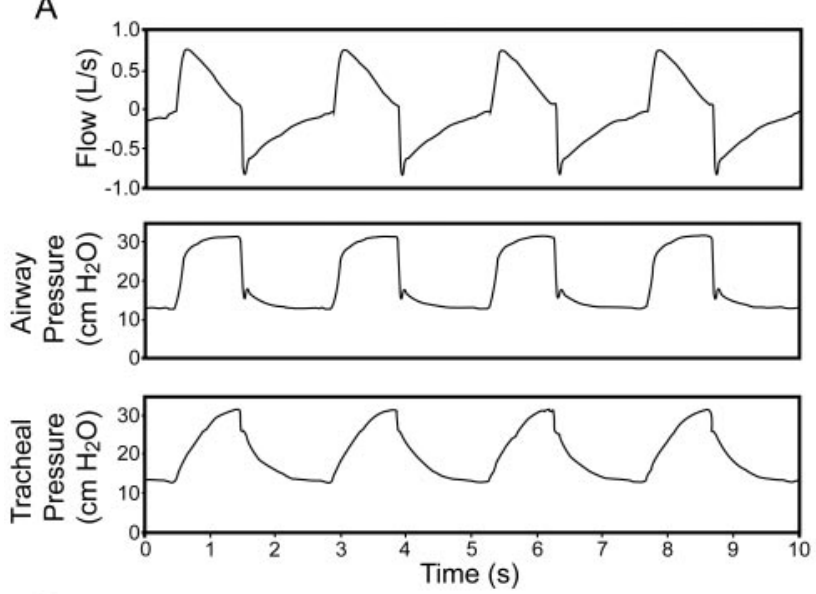

B
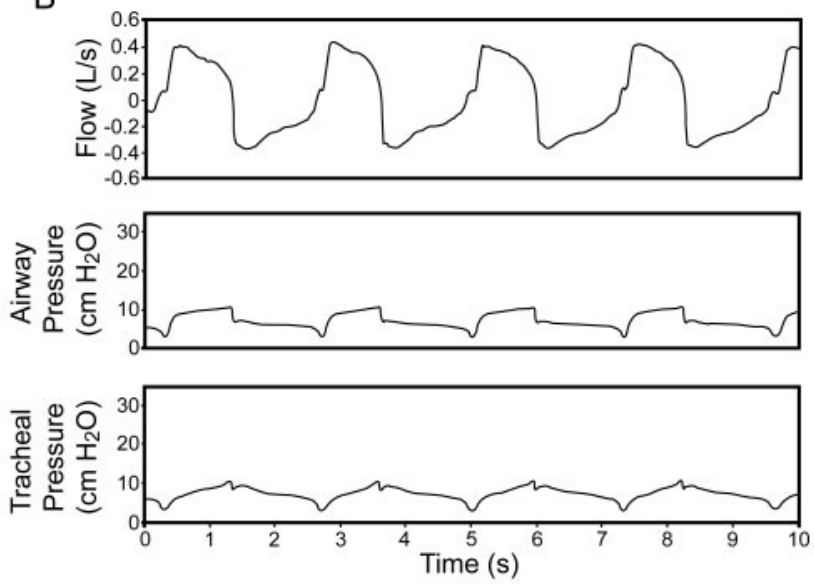

Fig. 2. Representative tracings of respiratory flow, airway pressure, and tracheal pressure, with a $7 \mathrm{~mm}$ inner diameter endotracheal tube, from patients during $(A)$ continuous mandatory ventilation mode and (B) a spontaneous breathing trial (CPAP plus pressure support).

tilation. The regression curves between minute ventilation $(\mathrm{L} / \mathrm{min})(\mathrm{x})$ and mean expiratory flow $(\mathrm{L} / \mathrm{s})(\mathrm{y})$ were $\mathrm{y}=0.029 \mathrm{x}+0.044\left(\mathrm{R}^{2}=0.89\right)$, according to the data from all patients. Representative tracings of respiratory flow, $\mathrm{P}_{\text {aw }}$, and $\mathrm{P}_{\text {trach }}$ from patients during CMV mode and SBT with $7 \mathrm{~mm}$ ID ETT are shown in Figure 2.

The relationships of imposed expiratory WOB $(\mathrm{J} / \mathrm{L})$ and $(\mathrm{J} / \mathrm{min})$ with mean expiratory flow are shown in Figures 3 and 4 , respectively. As mean expiratory flow increased, imposed expiratory WOB $(\mathrm{J} / \mathrm{L})$ and $(\mathrm{J} / \mathrm{min})$ increased in all groups. The regression curves between mean expiratory flow and imposed expiratory WOB (J/L) during SBT with both 7 and $8 \mathrm{~mm}$ ID ETT were not different. The regression curves between mean expiratory flow and imposed expiratory WOB (J/min) during SBT with $7 \mathrm{~mm}$ ID ETT and under CMV mode with $8 \mathrm{~mm}$ ID ETT were not different. However, the other combinations of regression curves were 

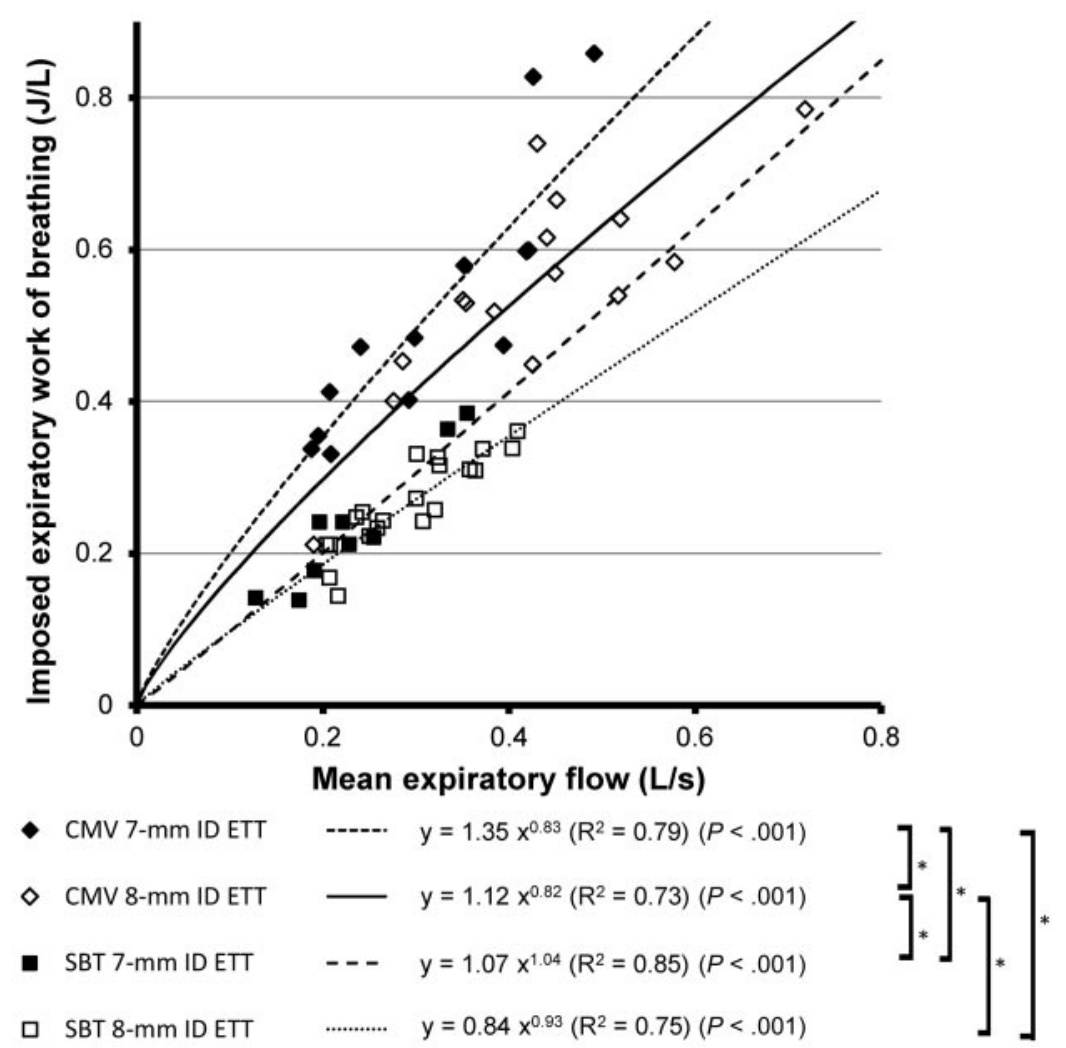

Fig. 3. Mean expiratory flow versus imposed expiratory work of breathing (WOB). CMV = continuous mandatory ventilation. ID $=$ inner diameter. $\mathrm{ETT}=$ endotracheal tube. $\mathrm{SBT}=$ spontaneous breathing trial. ${ }^{*} P<.05$.

significantly different. Levels of imposed expiratory WOB were affected by ID ETT and ventilatory mode.

The relationship of $\mathrm{R}_{\mathrm{E}}$ imposed by ETT and HME with mean expiratory flow is shown in Figure 5. As mean expiratory flow increased, $\mathrm{R}_{\mathrm{E}}$ imposed by the ETT and HME increased in all groups. The regression curves between mean expiratory flow and $\mathrm{R}_{\mathrm{E}}$ imposed by ETT and HME were different in all combinations. Smaller ETT size and CMV mode exhibited greater imposed $\mathrm{R}_{\mathrm{E}}$.

The relationship of ventilator-imposed $\mathrm{R}_{\mathrm{E}}$ to mean expiratory flow is shown in Figure 6. The correlation coefficients were not significant under CMV mode or SBT with $8 \mathrm{~mm}$ ID ETT. The correlation coefficients under CMV mode and SBT with $7 \mathrm{~mm}$ ID ETT were also relatively small. The regression curves between mean expiratory flow and ventilator-imposed $\mathrm{R}_{\mathrm{E}}$ under $\mathrm{CMV}$ mode with $7 \mathrm{~mm}$ ID ETT were not significantly different from those during SBT with $7 \mathrm{~mm}$ ID ETT. There was little effect of mean expiratory flow on ventilator-imposed $R_{E}$. Although the effects of ETT and ventilatory mode on ventilator-imposed $R_{E}$ were small, the values of ventilatorimposed $\mathrm{R}_{\mathrm{E}}$ in some patients under CMV mode were very large.

The relationship of the end-expiratory $\mathrm{P}_{\text {trach }}$-PEEP setting with mean expiratory flow is shown in Figure 7. As mean expiratory flow increased, end-expiratory $\mathrm{P}_{\text {trach }}{ }^{-}$ PEEP setting increased in all groups. The regression curves under CMV mode with both the 7 and $8 \mathrm{~mm}$ ID ETT were not different. Intrinsic PEEP caused by imposed $R_{E}$ would increase as mean expiratory flow increased.

\section{Discussion}

Under both CMV mode and SBT, imposed expiratory WOB increased with the increase in mean expiratory flow among patients undergoing invasive mechanical ventilation. Levels of imposed expiratory WOB were affected by the ID of the ETT and ventilator mode. The main reason for the increased imposed expiratory WOB is the increase in $R_{E}$ imposed by the ETT and HME. Although ventilatorimposed $R_{E}$ was relatively low and was not clearly related to mean expiratory flow, the ventilator-imposed $R_{E}$ was very large for some patients under CMV mode. As mean expiratory flow increased, the end-expiratory $\mathrm{P}_{\text {trach }}$-PEEP setting increased under both CMV mode and SBT. Intrinsic PEEP caused by imposed $R_{E}$ would increase as mean expiratory flow increased.

Few studies have measured $\mathrm{P}_{\text {trach }}$ during the expiratory phase in patients under mechanical ventilation. Stenqvist et al measured $\mathrm{P}_{\text {trach }}$ directly in 10 patients under mechan- 


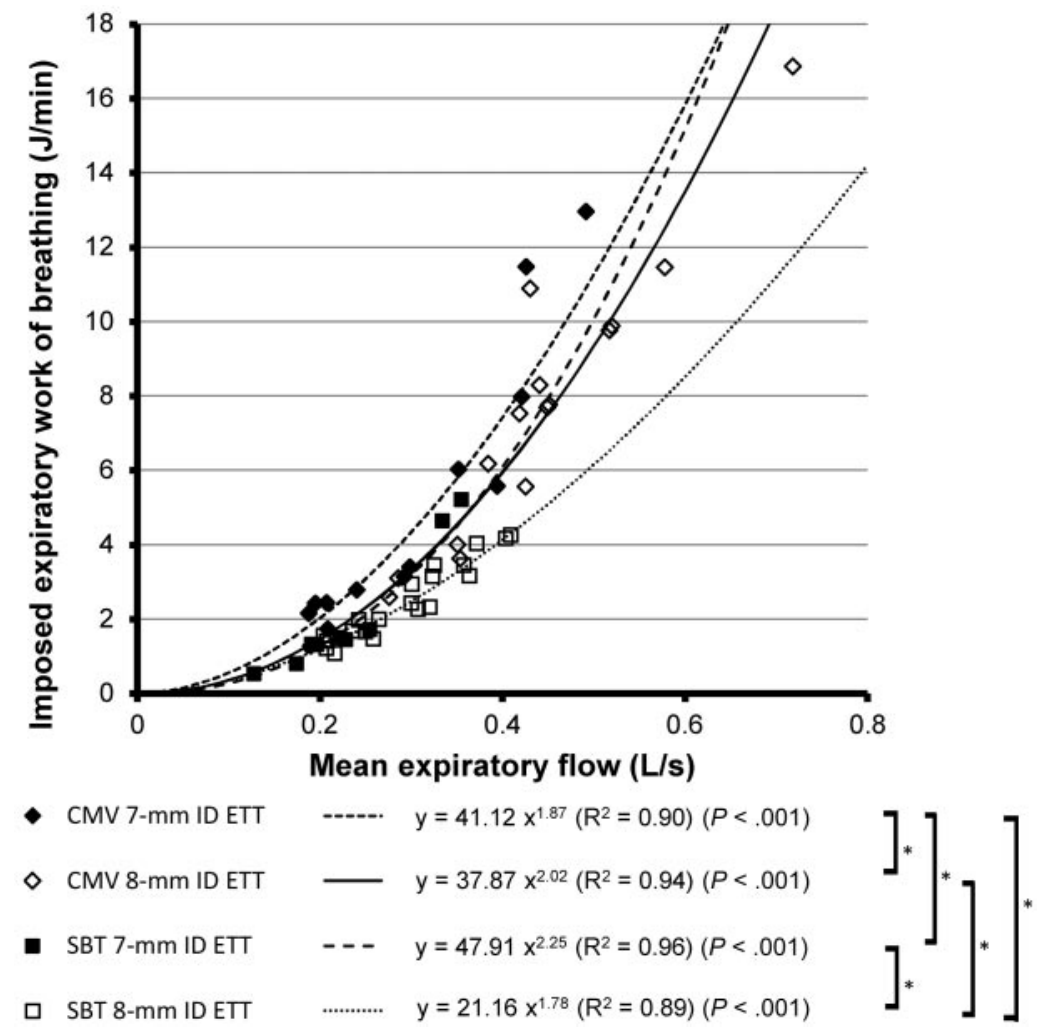

Fig. 4. Mean expiratory flow versus imposed expiratory work of breathing (WOB). CMV = continuous mandatory ventilation. ID $=$ inner diameter. $\mathrm{ETT}=$ endotracheal tube. SBT $=$ spontaneous breathing trial. ${ }^{*} P<.05$.

ical ventilation. ${ }^{18}$ Wrigge et al estimated $\mathrm{P}_{\text {trach }}$ using $\mathrm{P}_{\mathrm{aw}}$ and flow signals in patients with acute lung injury. ${ }^{19}$ They reported that end-expiratory $\mathrm{P}_{\text {trach }}$ was not different from end-expiratory $\mathrm{P}_{\mathrm{aw}}$ when using 7-8 mm ID ETT. In these studies, $\mathrm{P}_{\text {trach }}$ was not shown during the entire expiratory phase. We estimated $\mathrm{P}_{\text {trach }}$ during the whole respiratory cycle in patients under CMV mode and SBT.

It was appropriate to use WOB in order to evaluate the interaction between patient and ventilator, rather than simple $\mathrm{P}_{\mathrm{aw}}$ analysis. ${ }^{3-8,20}$ Although imposed inspiratory WOB has been examined in many studies, ${ }^{3-7}$ imposed expiratory WOB has not benefited from extensive study. We determined imposed expiratory WOB according to the definition used in previous studies.6,17 Because the extent of imposed expiratory WOB $(\mathrm{J} / \mathrm{L})$ increased as mean expiratory flow increased, imposed expiratory WOB $(\mathrm{J} / \mathrm{min})$ increased as a power function of mean expiratory flow. Patients under mechanical ventilation often need greater amounts of ventilation, involving higher expiratory flow, than do healthy subjects. ${ }^{14}$ The expiratory load imposed by an ETT, an HME, and an expiratory valve of the ventilator would therefore increase in the case of increased ventilatory demand.

The ID of the ETT affected the elevation of imposed expiratory WOB, with an increase in mean expiratory flow. The imposed $\mathrm{R}_{\mathrm{E}}$ from the ETT and HME was not constant, but a power function of mean expiratory flow, and was affected by the ID of the ETT. Therefore, the ID of the ETT was considered to be a determinant factor for imposed expiratory WOB, despite the absence of a significant difference in imposed expiratory WOB (J/L) during SBT between the $7 \mathrm{~mm}$ ID ETT and the $8 \mathrm{~mm}$ ID ETT. Extrapolation errors were considered to be the cause of this absence because of the fact that mean and peak expiratory flow values during SBT were relatively low.

Ventilatory mode was another factor affecting the elevation of imposed expiratory WOB. The CMV mode exhibited greater imposed $\mathrm{R}_{\mathrm{E}}$ of ETT and HME than in SBT. Under the CMV mode, higher inspiratory $\mathrm{P}_{\text {trach }}$ produced higher peak expiratory flow, which would increase imposed $R_{E}$ of ETT and HME. Ventilator-imposed $R_{E}$ is also related to the difference in imposed expiratory WOB between CMV mode and SBT. Although ventilator-imposed $R_{E}$ was relatively low and was not clearly related to mean expiratory flow, ventilator-imposed $R_{E}$ was very large for some patients under CMV mode. The dissociation between the expiratory phase of the ventilator and the patient's expiration would increase imposed expiratory WOB. Under the CMV mode, regression analysis of numbers of assist ventilation, which was derived from breathing frequency minus ventilatory frequency setting, to ventilatorimposed $R_{E}$ is shown in Figure 8. As numbers of assisted 


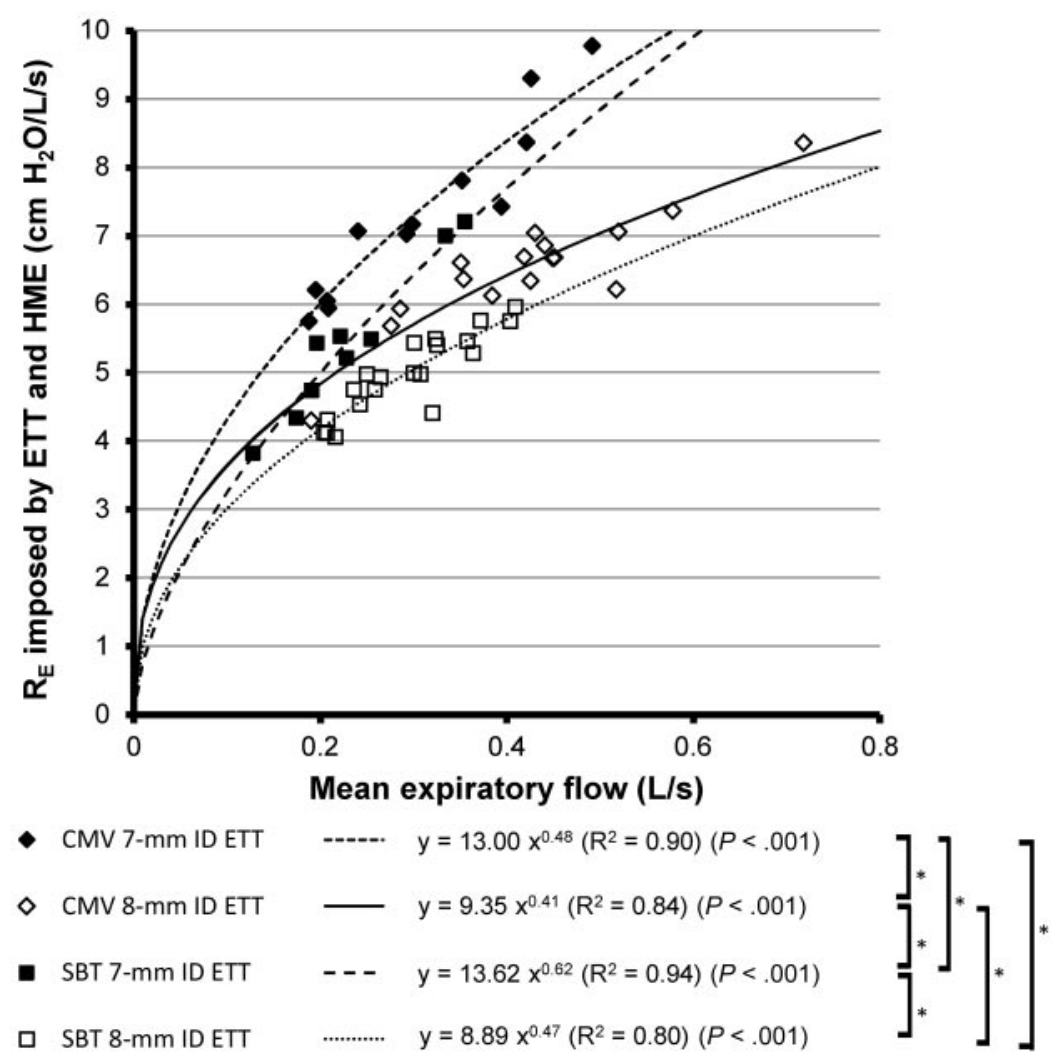

Fig. 5. Mean expiratory flow versus imposed expiratory resistance $\left(R_{E}\right)$ by the endotracheal tube $(E T T)$ and the heat and moisture exchanger (HME). CMV = continuous mandatory ventilation. ID = inner diameter. ETT = endotracheal tube. SBT = spontaneous breathing trial. ${ }^{*} P<.05$.

ventilations increased, ventilator-imposed $R_{E}$ increased. Asynchrony between the ventilatory setting and patient respiratory effort may exist in such patients. If the inspiratory time setting under CMV mode is too long, expiration begins at a high $\mathrm{P}_{\mathrm{aw}}{ }^{21}$ Because PSV has an expiratory triggering function different from that of CMV mode, the possibility of the asynchrony between ventilatory setting and patient's respiratory effort might be small. The expiratory triggering setting of PSV is thought to affect imposed expiratory WOB. The differences in imposed expiratory WOB between the CMV mode and SBT may also be derived from extrapolation errors because of the fact that mean expiratory flow values were uniformly higher during CMV, compared with those during the SBT. No further conclusion about the expiratory function of the ventilator was obtained from the present findings, and future research will be needed to resolve this.

\section{Clinical Implications}

In quiet or passive breathing, when expiration is performed only by the elasticity of the respiratory system, expiratory WOB would need additional lung inflation at the end of inspiration. Hyperinflation of the lung can in- duce lung damage. ${ }^{10,13}$ Although we did not measure intrinsic PEEP in the present study, the end-expiratory $\mathrm{P}_{\text {trach }}{ }^{-}$ PEEP setting increased as mean expiratory flow increased. Intrinsic PEEP caused by imposed $R_{E}$ would increase as ventilation levels increase. In a lung model study, Haberthür et al reported that an increase in minute ventilation increased the volume of air trapping and levels of intrinsic PEEP in mechanical ventilation with both 7 and $8 \mathrm{~mm}$ ID ETTs. ${ }^{22}$

The settings of PEEP under mechanical ventilation for patients with acute lung injury have been discussed, and intrinsic PEEP is thought to be a crucial factor. ${ }^{23,24}$ The present study indicated that the levels of minute ventilation affected $\mathrm{P}_{\text {trach }}$ during the expiratory phase. $\mathrm{P}_{\text {trach }}$ should be considered in order to determine PEEP in patients with acute lung injury. In patients capable of spontaneous breathing, intrinsic PEEP acts as an inspiratory threshold load and increases inspiratory WOB. ${ }^{13,25}$ Intrinsic PEEP also impairs triggering of the ventilator, which would induce dissociation of the ventilator and the patient's breathing efforts. ${ }^{13}$ Moreover, this dissociation would likely increase intrinsic PEEP by increasing $\mathrm{P}_{\text {trach }}$.

SBT assumes the role of simulating respiratory load in the post-extubation period. Because the setting level of PSV affected patients' inspiratory WOB in PSV mode, the 

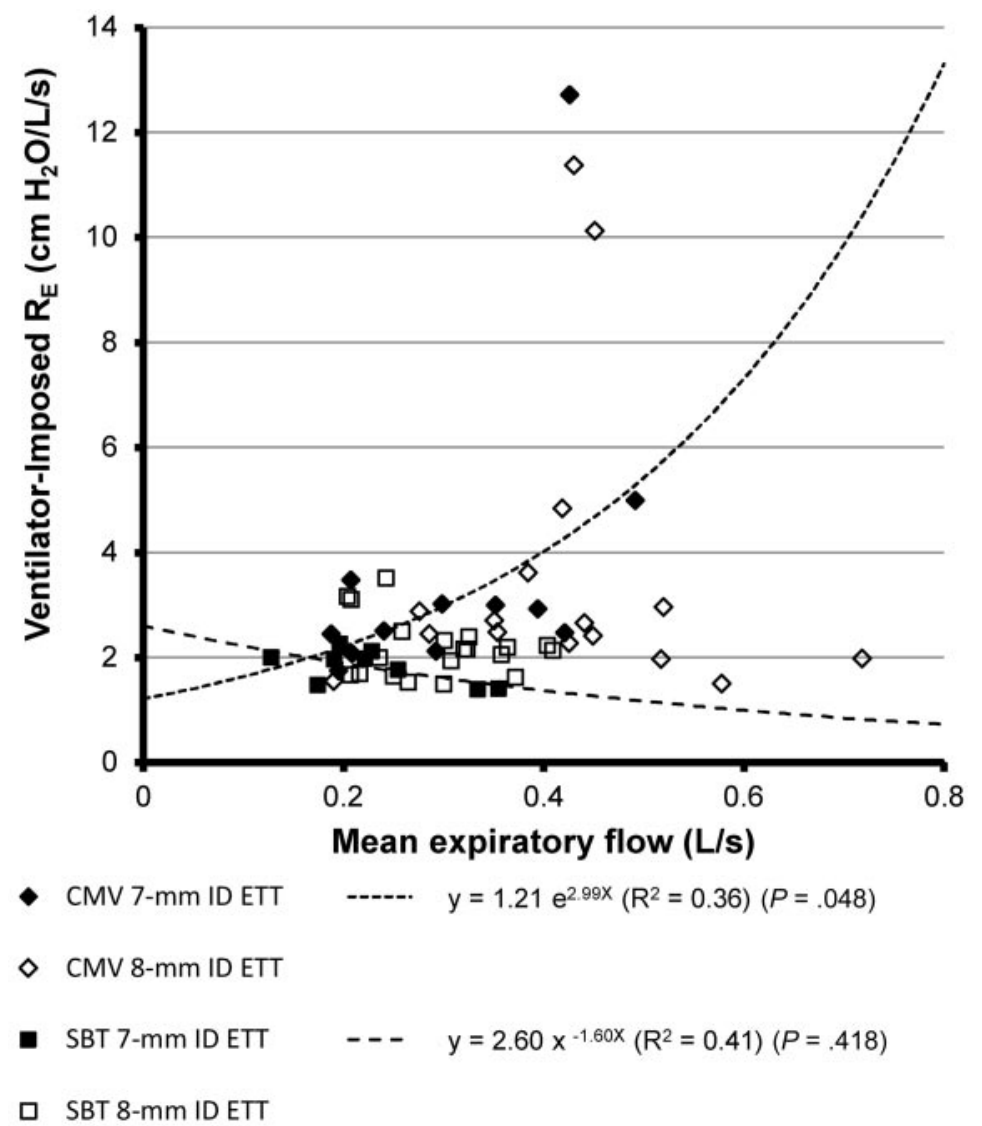

Fig. 6. Mean expiratory flow versus ventilator-imposed expiratory resistance $\left(R_{E}\right)\left(\mathrm{cm} \mathrm{H}_{2} \mathrm{O} / \mathrm{L} / \mathrm{s}\right)$. There are no significant differences between the regression curves. CMV $=$ continuous mandatory ventilation. ID $=$ inner diameter. $\mathrm{ETT}=$ endotracheal tube. SBT $=$ spontaneous breathing trial.

appropriate settings provided the same level of patients' inspiratory WOB in the post-extubation period. ${ }^{5}$ Brochard et al reported that the PSV level compensating for additional WOB by the ETT and ventilator was $5.7 \mathrm{~cm} \mathrm{H}_{2} \mathrm{O}$ in patients free of intrinsic lung disease. ${ }^{5}$ Because we used a PSV level of $5 \mathrm{~cm} \mathrm{H}_{2} \mathrm{O}$ in the present study, patients' inspiratory WOB level was not very different from that at post-extubation level. In contrast, patients' expiratory WOB during SBT has rarely been investigated. A portion of patients' expiratory WOB during SBT is derived from imposed expiratory WOB. Elsasser et al measured imposed expiratory WOB under CPAP mode in a lung model. ${ }^{6}$ In agreement with the results of the present study, they reported that an increase in minute ventilation increased imposed expiratory WOB. Straus et al reported that WOB dissipated in the supraglottic airway, with extubation values of $0.12 \mathrm{~J} / \mathrm{L}$ and $1.97 \mathrm{~J} / \mathrm{min}$, which were less than those for imposed expiratory WOB in the present study. ${ }^{8} \mathrm{Be}-$ cause an increase in imposed expiratory WOB would need additional expiratory effort from the patient, it is possible that an increase in imposed expiratory WOB would affect the results of SBT, especially in patients with high minute ventilation.

\section{Limitations}

In previous studies, $\mathrm{P}_{\text {trach }}$ was measured directly using a small measuring tube inserted into the trachea through the ETT. ${ }^{16,26,27}$ However, direct measurement by this method raises several concerns. First, the insertion of the measuring tube itself would increase the resistance of the ETT. Second, the high resistance of the small measuring tube would create a time delay and interfere with the accuracy of the pressure curve of $P_{\text {trach }}$. Third, the position of the tip of the measuring tube would affect the data. ${ }^{16,26}$ Therefore, we used a calculated figure for $\mathrm{P}_{\text {trach }}$ to assess expiratory load, rather than an actual measurement. Although previous reports indicated the accuracy of this method of calculating $\mathrm{P}_{\text {trach }},{ }^{15,19}$ concerns about the discrepancy between calculated and actual values remain. For example, this could occur at the end of expiration when calculated pressure differences through the ETT theoretically decrease to 
Estimation of Tracheal Pressure and Imposed Expiratory Work of Breathing

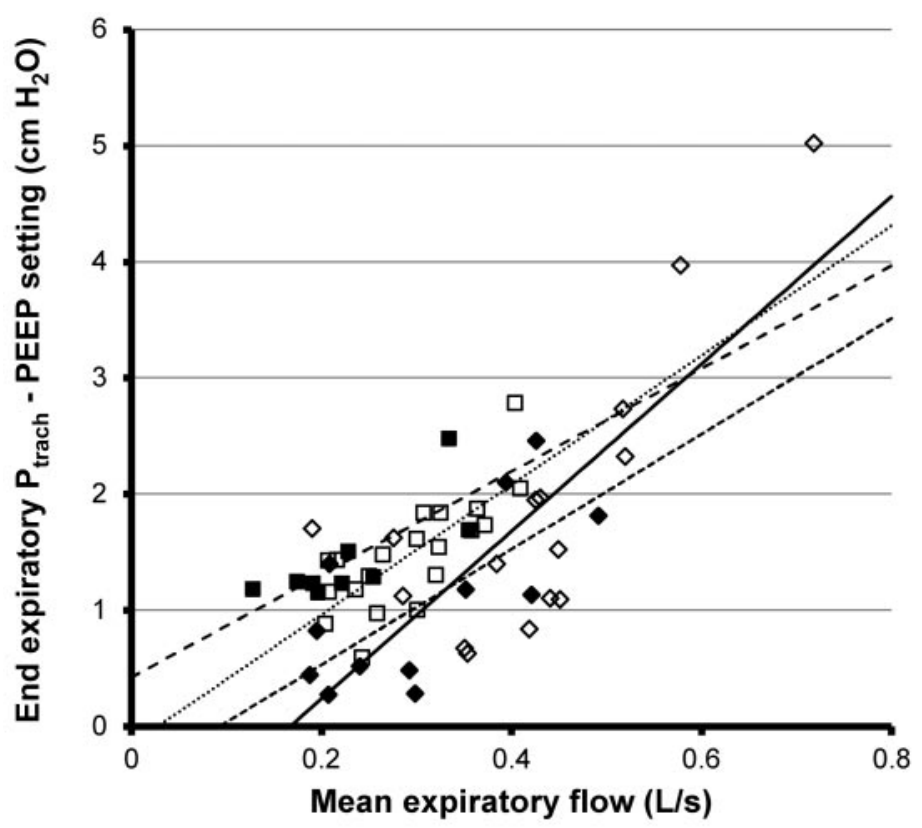

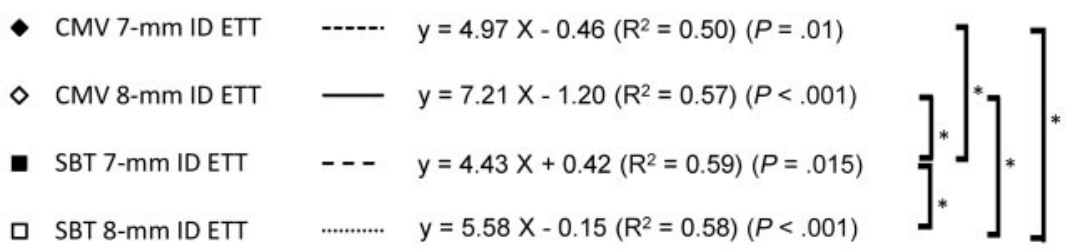

Fig. 7. Mean expiratory flow versus end-expiratory tracheal pressure $\left(P_{\text {trach }}\right)-P E E P$ setting. $C M V=$ continuous mandatory ventilation. ID $=$ inner diameter. ETT = endotracheal tube. SBT $=$ spontaneous breathing trial. ${ }^{*} P<.05$.

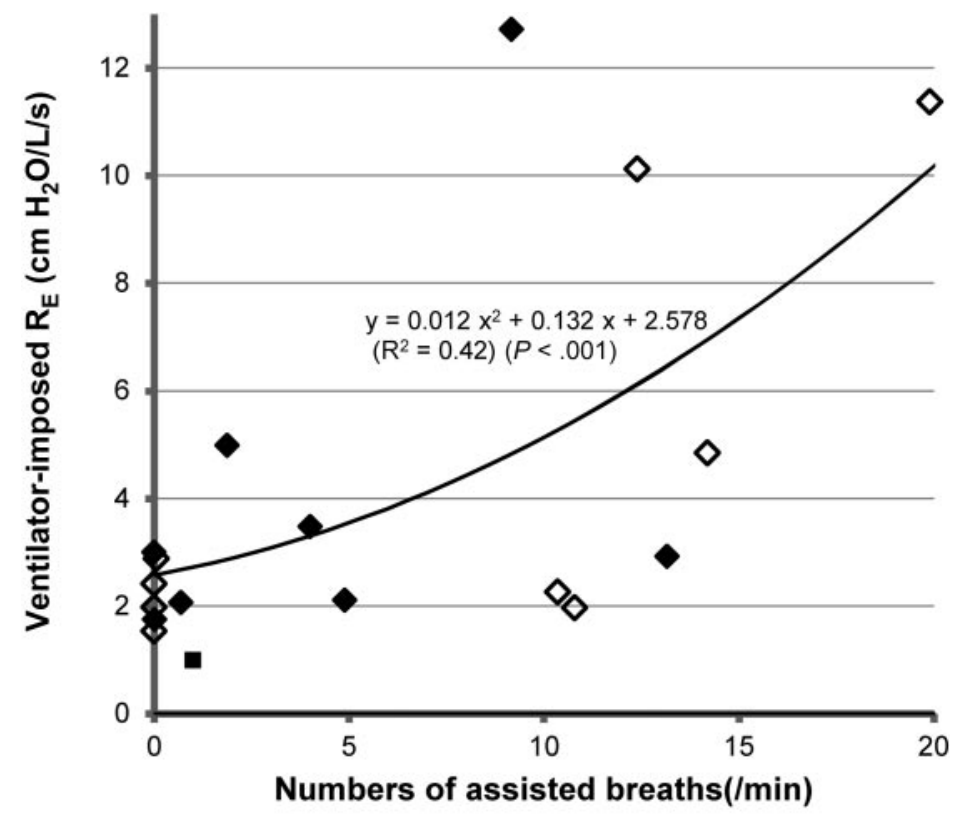

- CMV 7-mm ID ETT

$\diamond$ CMV 8-mm ID ETT

Fig. 8. Numbers of assisted breaths per minute versus ventilator-imposed expiratory resistance $\left(R_{E}\right)$ during continuous mandatory ventilation. The number of assisted breaths was calculated as breathing frequency - set ventilatory rate. 


\section{Estimation of Tracheal Pressure and Imposed Expiratory Work of Breathing}

zero, due to respiratory zero flow. This introduces the possibility of underestimating the calculated $\mathrm{P}_{\text {trach }}$. Furthermore, bending of the ETT and attachment of secretions on its inner surface would make the resistance of the ETT larger than the calculated value. ${ }^{28,29}$ Although there was no clear evidence of bending of the ETT or narrowing of the ETT by secretions, the possibility of underestimating $\mathrm{P}_{\text {trach }}$ remains.

In passive expiration, measurement of intrinsic PEEP is useful to evaluate the effects of imposed expiratory WOB. Inspiratory holding with relaxation or deep sedation is needed to measure intrinsic PEEP. Because most of our patients were lightly sedated, we did not perform inspiratory holding. Instead, we calculated the end-expiratory $\mathrm{P}_{\text {trach }}$-PEEP setting. While the main focus of the present study was imposed expiratory work, measurement of esophageal pressure is preferable in evaluating patients' intrinsic PEEP and active expiratory work load. Because insertion of an esophageal balloon and fine adjustment of the position and volume of the balloon are needed to measure esophageal pressure, this could not be measured in the present study. In a future study, examination of patients' expiratory work should be performed.

Because the $\mathrm{P}_{\mathrm{aO}_{2}} / \mathrm{F}_{\mathrm{IO}_{2}}$ was greater than $200 \mathrm{~mm} \mathrm{Hg}$ in most of the study patients, the degree of lung injury was relatively small. The ratio of tidal volume to ideal body weight in our study was in the range $8-10 \mathrm{~mL} / \mathrm{kg}$. Patients' lung characteristics and ventilatory settings would affect imposed expiratory WOB. Further research is needed to evaluate imposed expiratory WOB in patients with severe lung injury.

We used only one type of ventilator. Because ventilator performance was thought to affect the results of the study, other ventilators would produce different data. However, because the ventilator we used was the most up-to-date available, similar problems would likely exist for other ventilators.

\section{Conclusions}

In conclusion, $\mathrm{P}_{\text {trach }}$ was measured under $\mathrm{CMV}$ mode and during SBT in patients receiving mechanical ventilation. We calculated imposed expiratory WOB by an ETT, an HME, and the expiratory valve of the ventilator. Imposed expiratory WOB increased as mean expiratory flow increased in both modes. Under mechanical ventilation, $\mathrm{P}_{\text {trach }}$ should be considered, especially in patients with higher minute ventilation.

\section{REFERENCES}

1. Kelly M, Gillies D, Todd DA, Lockwood C. Heated humidification versus heat and moisture exchangers for ventilated adults and children. Cochrane Database Syst Rev 2010;14(4):CD004711.
2. American Association for Respiratory Care. AARC clinical practice guideline. Humidification during mechanical ventilation. Respir Care 1992;37(8):887-890.

3. Fabry B, Haberthür C, Zappe D, Guttmann J, Kuhlen R, Stocker R. Breathing pattern and additional work of breathing in spontaneously breathing patients with different ventilatory demands during inspiratory pressure support and automatic tube compensation. Intensive Care Med 1997;23(5):545-552.

4. Messinger G, Banner MJ, Blanch PB, Layon AJ. Using tracheal pressure to trigger the ventilator and control airway pressure during continuous positive airway pressure decreases work of breathing. Chest 1995;108(2):509-514.

5. Brochard L, Rua F, Lorino H, Lemaire F, Harf A. Inspiratory pressure support compensates for the additional work of breathing caused by the endotracheal tube. Anesthesiology 1991;75(5):739745.

6. Elsasser S, Guttmann J, Stocker R, Mols G, Priebe HJ, Haberthür C. Accuracy of automatic tube compensation in new-generation mechanical ventilators. Crit Care Med 2003;31(11):2619-2626.

7. Bersten AD, Rutten AJ, Vedig AE, Skowronski GA. Additional work of breathing imposed by endotracheal tubes, breathing circuits, and intensive care ventilators. Crit Care Med 1989;17(7): 671-677.

8. Straus C, Louis B, Isabey D, Lemaire F, Harf A, Brochard L. Contribution of the endotracheal tube and the upper airway to breathing workload. Am J Respir Crit Care Med 1998;157(1):23-30.

9. Fabry B, Haberthur C, Zappe D, Guttmann J, Kuhlen R, Stocker R. Automatic compensation of endotracheal tube resistance in spontaneously breathing patients. Technol Health Care 1994;1: 281-291.

10. Pepe PE, Marini JJ. Occult positive end-expiratory pressure in mechanically ventilated patients with airflow obstruction: the auto-PEEP effect. Am Rev Respir Dis 1982;126(1):166-170.

11. Williams TJ, Tuxen DV, Scheinkestel CD, Czarny D, Bowes G. Risk factors for morbidity in mechanically ventilated patients with acute severe asthma. Am Rev Respir Dis 1992;146(3):607-615.

12. Sinderby C, Spahija J, Beck J, Kaminski D, Yan S, Comtois N, Sliwinski P. Diaphragm activation during exercise in chronic obstructive pulmonary disease. Am J Respir Crit Care Med 2001;163(7): 1637-1641.

13. Navalesi P, Maggiore SM. Positive end-expiratory pressure. In: Tobin MJ, editor. Principle \& practice of mechanical ventilation. New York: McGraw-Hill; 2006:273-325.

14. The Acute Respiratory Distress Syndrome Network. Ventilation with lower tidal volumes as compared with traditional tidal volumes for acute lung injury and the acute respiratory distress syndrome. N Engl J Med 2000;342(18):1301-1308.

15. Guttmann J, Eberhard L, Fabry B, Bertschmann W, Wolff G. Continuous calculation of intratracheal pressure in tracheally intubated patients. Anesthesiology 1993;79(3):503-513.

16. Navalesi P, Hernandez P, Laporta D, Landry JS, Maltais F, Navajas $\mathrm{D}$, et al. Influence of site of tracheal pressure measurement on in situ estimation of endotracheal tube resistance. J Appl Physiol 1994; 77(2):2899-2906.

17. DiBlasi RM, Salyer JW, Zignego JC, Redding GJ, Richardson CP. The impact of imposed expiratory resistance in neonatal mechanical ventilation: a laboratory evaluation. Respir Care 2008;53(11):14501460.

18. Stenqvist O, Sonander H, Nilsson K. Small endotracheal tubes: ventilator and intratracheal pressures during controlled ventilation. $\mathrm{Br} \mathrm{J}$ Anaesth 1979;51(4):375-381.

19. Wrigge H, Zinserling J, Hering R, Schwalfenberg N, Stüber F, von Spiegel T, et al. Cardiorespiratory effects of automatic tube 
compensation during airway pressure release ventilation in patients with acute lung injury. Anesthesiology 2001;95(2):382-389.

20. Bolder PM, Healy TE, Bolder AR, Beatty PC, Kay B. The extra work of breathing through adult endotracheal tubes. Anesth Analg 1986;65(8):853-859.

21. Amato MB, Marini JJ. Pressure-controlled and inverse-ratio ventilation. In: Tobin MJ, editor. Principle \& practice of mechanical ventilation. New York: McGraw-Hill; 2006:251-272.

22. Haberthür C, Mehlig A, Stover JF, Schumann S, Möller K, Priebe $\mathrm{HJ}$, et al. Expiratory automatic endotracheal tube compensation reduces dynamic hyperinflation in a physical lung model. Crit Care 2009;13(1):R4.

23. Brower RG, Lanken PN, MacIntyre N, Matthay MA, Morris A, Ancukiewicz M, et al.; National Heart, Lung, and Blood Institute ARDS Clinical Trials Network. Higher versus lower positive endexpiratory pressures in patients with the acute respiratory distress syndrome N Engl J Med 2004;351(4):327-336.

24. de Durante G, del Turco M, Rustichini L, Cosimini P, Giunta F, Hudson LD, et al. ARDSNet lower tidal volume ventilatory strategy may generate intrinsic positive end-expiratory pressure in patients with acute respiratory distress syndrome. Am J Respir Crit Care Med 2002;165(9):1271-1274.

25. Coussa ML, Guérin C, Eissa NT, Corbeil C, Chassé M, Braidy J, et al. Partitioning of work of breathing in mechanically ventilated COPD patients. J Appl Physiol 1993;75(4):1711-1709.

26. Sondergaard S, Kárason S, Wiklund J, Lundin S, Stenqvist O. Alveolar pressure monitoring: an evaluation in a lung model and in patients with acute lung injury. Intensive Care Med 2003;29(6):955962.

27. Kárason S, Søndergaard S, Lundin S, Wiklund J, Stenqvist O. Direct tracheal airway pressure measurements are essential for safe and accurate dynamic monitoring of respiratory mechanics. A laboratory study. Acta Anaesthesiol Scand 2001;45(2):173-179.

28. El-Khatib MF, Husari A, Jamaleddine GW, Ayoub CM, BouKhalil P. Changes in resistances of endotracheal tubes with reductions in the cross-sectional area. Eur J Anaesthesiol 2008;25(4): 275-279.

29. Wilson AM, Gray DM, Thomas JG. Increases in endotracheal tube resistance are unpredictable relative to duration of intubation. Chest 2009;136(4):1006-1013.

This article is approved for Continuing Respiratory Care Education credit. For information and to obtain your CRCE

(free to AARC members) visit www.rcjournal.com 